\title{
IMPLICAÇÕES DA LEGISLAÇÃO SIMBÓLICA NO SISTEMA JURÍDICO
}

\author{
Patricia Barbosa Nogueira ${ }^{1}$ \\ Cristiano Batista ${ }^{2}$
}

\section{RESUMO:}

Em termos teóricos, o artigo coloca em discussão à edição de textos legais que prestam à função política em detrimento à função normativo-jurídico: o que Neves conceitua como Legislação Simbólica. Delimitar-se-á o significado de simbólico, apresentando o modelo tricotômico de Kindermann: confirmar valores sociais; demonstrar capacidade de ação do Estado e, adiar solução de conflitos sociais. Abordaremos a transição de Legislação Simbólica para Constitucionalização Simbólica, fixando, com base em Luhmann, a diferenciação da autopoiese e alopoiese do direito. Por fim, abordaremos as implicações da Constitucionalização Simbólica para o Sistema Jurídico, sendo a principal: a Corrupção Sistémica.

Palavras-chave: Legislação Simbólica; autopoiese; função político ideológico; função normativo jurídico; corrupção sistêmica.

\section{IMPLICATIONS OF SYMBOLIC LEGISLATION IN THE LEGAL SYSTEM}

\begin{abstract}
:
In theoretical terms, the article puts in discussion the edition of legal texts that lend to the political function to the detriment of the normative-juridical function: what Neves conceptualizes like Symbolic Legislation. The meaning of symbolic will be delimited, presenting Kindermann's trichotomic model: confirming social values; Demonstrate the state's capacity for action and postpone resolution of social conflicts. We will approach the transition from Symbolic Legislation to Symbolic Constitutionalisation, establishing, based on Luhmann, the differentiation of autopoiesis and allopathies of the law. Finally, we will cover the implications of Symbolic Constitutionalisation for the Legal System, the main being: Systemic Corruption.
\end{abstract}

Keywords: Symbolic Legislation; autopoiesis; politic ideological function; normative legal function; corruption systemic.

\section{INTRODUÇÃO:}

O presente trabalho tem como temática a Legislação Simbólica, teoria desenvolvida por Marcelo Neves no ano de 1992 para obtenção do cargo de professor titular da Universidade Federal de Pernambuco, cuja primeira versão foi publicada no Brasil em 1994, pela Editora Acadêmica, sem, entretanto, conseguir devida visibilidade que, apenas obteve

\footnotetext{
${ }^{1}$ Mestranda em Proteção dos Direitos Fundamentais pela Universidade de Itaúna - UIT; Especialista em Direito Empresarial pela Pontifícia Anamages; Graduada em Direito pela FADOM.

${ }^{2}$ Mestrando em Proteção dos Direitos Fundamentais pela Universidade de Itaúna - UIT; Graduado em Direito pela FADOM.
} 
amplo destaque quando da publicação pela editora alemã Dunckerund Humblot no ano de 1998. Em 2007 foi reeditada pela editora Martins Fontes em uma versão revista, ampliada e atualizada do texto alemão, intitulada a Constitucionalização Simbólica.

A obra inicia com uma rigorosa e detalhada delimitação do termo simbólico, exatamente por ser um termo ambíguo e vago e, que não raras vezes, por não haver uma predefinição, leva a entendimentos equivocados. Para tanto, Marcelo Neves apresenta diversas conceituações até uma efetiva delimitação semântica da expressão "Legislação Simbólica" justificando que dar uma mera definição terminológica não seria suficiente, pois ainda assim haveria variação, como ocorre na psicanálise, onde Froid, Lacan e Iung usam o termo simbólico, mas com sentidos diferentes e, por haver dentro da mesma ciência uma grande variação no emprego do termo, era necessária a delimitação semântica, uma predefinição do significado de simbólico no contexto de Legislação Simbólica que implica em um deslocamento de um sentido para uma outra esfera de significações, ou seja, o termo usado tinha sentido manifesto, mas este sentido manifesto não era tão relevante, pois o relevante era o seu significado latente.

Neste contexto, o discurso conotativo era muito mais forte que o discurso denotativo. A linguagem manifesta era mais frágil que a linguagem latente. O significado latente prevalece sobre o significado manifesto, havendo o predomínio ou hipertrofia da função simbólica em detrimento da função normativo-jurídico, o que é definido como Legislação Simbólica. E, nesse sentido, a Legislação Simbólica consistiria na produção de textos cuja referência manifesta à realidade é normativo-jurídico, mas que serve, primária e hipertroficamente, a finalidades políticas de caráter não especificamente normativo-jurídico.

Delimitado o termo simbólico e definida o que é Legislação Simbólica, Marcelo Neves, embasado nos estudos de Harald Kindermann, adere à tipologia tricotômica para demonstrar a hipertrofia das finalidades políticas em detrimento ao normativo-jurídico, onde a primeira serve tão-somente para confirmar valores sociais, sendo secundária a eficácia normativa da respectiva lei; a segunda, objetiva fortificar a confiança dos cidadãos no respectivo governo, demonstrando a capacidade de ação do Estado, em uma clara legislação álibi que busca aparente solução para problemas da sociedade, mesmo que mascarando a realidade, ou seja, descarrega as pressões políticas, apresentando o Estado como sensível às exigências e expectativas dos cidadãos, mas de fato não apenas deixa os problemas sem 
solução, como obstrui o caminho para eles sejam resolvidos e, por fim, apresenta-se a terceira como fórmula de compromissos dilatórios, criando-se leis que na verdade apenas adiam a solução dos conflitos sociais, transferindo a solução de conflitos para um futuro indeterminado, sendo que em todos não se esta comprometido em dar efetividade ao diploma normativo, mas sim usar a legislação para interesses políticos, ludibriando os cidadão.

Compreendido o conceito de Legislação Simbólica, Neves sob forte influência do modelo sistêmico proposto por Niklas Luhmann, propõe um debate sobre a Constitucionalização Simbólica, definindo "Constituição" em termos de acoplamento estrutural entre os sistemas político e jurídico, que como mecanismo permite a autonomia operacional do direito na sociedade moderna, ou seja, a autopoiese que é a auto-reprodução de um sistema por meio de seu código-diferença, mas que em razão da "corrupção do sistema" ocorre exatamente o oposto disso, ou seja, os elementos de outro sistema, sem passarem pelo filtro do código-diferença de um determinado subsistema, entram e permanecem neste ocorrendo o que o autor define como alopoiese que no contexto simbólico refere-se à sobreposição do sistema político ao jurídico.

Por fim, é levantada a problemática da perda da autonomia operacional, pois se ao definir a Constituição como acoplamento estrutural, entre direito e política, deveria haver autonomia operacional entre ambos. Contudo, em se tratando de Constituições Simbólicas o que se percebe é exatamente o contrário: a "alopoiese" do direito.

Desta feita, o presente trabalho através do estudo e análise do livro a Constitucionalização Simbólica objetiva apresentar os efeitos e consequências das Legislações Simbólicas que possuem função política mais forte que a função normativojurídica, uma hipertrofia da função político-simbólica em detrimento da função normativojurídica, que impede a concretização do texto Constitucional.

Para a realização do artigo foi utilizado o método dedutivo, partindo das premissas abordadas na obra de Marcelo Neves intitulada Constitucionalização Simbólica e análise das teorias desenvolvidas por Kindermann e Luhmann, possibilitando levantamento e apontamento das implicações da Legislação Simbólico para Sistema Jurídico. A técnica utilizada foi pesquisa bibliográfica em livros e artigos. 


\section{DELIMITAÇÃO DE SIMBÓliCO E SIGNIFICADO DE LEGISLAÇÃo SIMBÓLICA}

Como explicitado, dar uma mera definição terminológica ao termo simbólico não é suficiente, pois conforme ressaltado por Neves este é um dos termos mais ambíguos dentro da semântica, impondo por consequência uma delimitação para que não ocorra ambiguidade visto sua grande variação até mesmo dentro da mesma ciência, situação exemplificado pela psicanálise onde autores como Froid, Lacan e Iung usam o termo simbólico, mas com sentidos diferentes, sendo necessária uma delimitação semântica, uma predefinição do significado de simbólico no contexto de Legislação Simbólica.

E foi na Alemanha no ano de 1987 que Marcelo Neves observando um debate sobre Legislação Simbólica passou a perceber que os autores tratavam aquilo inocentemente, sem profunda reflexão.

Sabiam do que estavam tratando, mas não tinham uma clareza, uma definição do termo simbólico, o que despertou em Neves a necessidade da delimitação, que naquele contexto do debate, implicava em um deslocamento de sentido para uma outra esfera de significações, ou seja, o termo usado tinha sentido manifesto, mas este sentido manifesto não era tão relevante.

O relevante é o seu significado latente. O discurso conotativo era muito mais forte que o discurso denotativo. A linguagem manifesta é mais frágil que a linguagem latente. $\mathrm{O}$ significado latente prevalece sobre o significado manifesto que neste sentido "aponta para o predomínio, ou mesmo hipertrofia, no que se refere ao sistema jurídico, da função simbólica da atividade legiferante e do seu produto, a lei, sobretudo em detrimento da função jurídiconormativa" (NEVES, 2007, p. 23).

Exemplo aclarador é a palavra democracia, que tem uma carga simbólica tão forte que a dimensão manifesta: A República Democrática da Alemanha, um regime totalitário, usava este termo por causa da sua força simbólica.

Isso que é simbólico no contexto da Legislação Simbólica.

Traçados a delimitação de simbólico, Marcelo Neves, define que a Legislação Simbólica consiste na produção de textos, leis, que prestam primariamente e 
hipertroficamente, a finalidades políticas em detrimento do normativo-jurídico, havendo uma hipertrofia da função simbólica dos textos em detrimento da efetiva concretização jurídiconormativa de seus preceitos, o que impede a solução concreta de conflitos sociais e principalmente a efetivação dos direitos fundamentais:

Considerando-se que a atividade legiferante constitui um momento de confluência concentrada entre sistema político e jurídico, pode-se definir a legislação simbólica como produção de textos cujas referências manifesta à realidade é normativa jurídica, mas que serve, primária e hipertroficamente, a finalidades políticas de caráter não especificamente normativo-jurídico (NEVES, 2007, p. 30).

Neste contexto, a função simbólica existe "quando o legislador se restringe a formular uma pretensão de produzir normas, sem tomar qualquer providência no sentido de criar os pressupostos para a eficácia, apesar de estar em condições de criá-los (NEVES, 2007, p. 31), pois o objeto não é regular condutas humanas, mas atender os interesses políticos.

\section{TIPOS DE LEGISLAÇÃO SIMBÓLICA}

Traçado a delimitação semântica do termo simbólico e definida o que é Legislação Simbólica, Marcelo Neves, com fundamento e sob influência de Horald Kindermann, apresenta um modelo tricotômico classificando a Legislação Simbólica em confirmadora de valores sociais, demonstrar a capacidade de ação do Estado e, adiar a solução de conflitos sociais através de compromissos dilatórios.

A primeira tem por função confirmar valores sociais, ou seja, a Legislação Simbólica presta a confirmação de valores sociais de um grupo em detrimento de outro. Exemplo apresentado refere-se à lei seca dos USA que não foi elaborada para ter força normativa reguladora de conduta (coibir ou reduzir o uso do álcool e, consequentemente, seus efeitos), mas sim para confirmar os valores sociais dos nativos protestantes contra o grupo do imigrante católico que chegava e tinha o hábito de beber. A legislação foi elaborada como fórmula de glorificar um grupo, demonstrando a superioridade ou predominância social de determinada concepção valorativa, sendo secundária a eficácia normativa da respectiva lei e, neste aspecto, deve ser destacado que "nunca se bebeu tanto quanto na vigência da lei seca".

A legislação álibi propõe demonstrar a capacidade de ação do Estado, na qual se cria uma imagem favorável do Estado no que concerne à resolução de problemas sociais, produzindo confiança no sistema político. 
Desta feita, para satisfazer as expectativas dos cidadãos elabora-se legislação sem que haja o mínimo de condições de efetivação das respectivas normas, ou seja, o legislador evita pressões políticas ou apresenta o Estado como sensível às exigências e expectativas dos cidadãos. E, neste sentido importante observar que a legislação álibi sempre encontra terreno fértil quando há uma comoção pública, quando há problemas relevantes que chocam e, diante das exigências do público aflito, o Estado reage apresentando um álibi para acalmar os ânimos e tranquilizar o público.

O exemplo apresentado pelo autor refere-se ao ocorrido em 1987 quando pessoas idosas hospedadas na região do Mar do Norte foram contaminadas por peixes, vindo alguns a óbito. O fato não apenas gerou grande comoção pública como afetou a economia local que sobrevivia do turismo destinada a esta classe social. Diante das exigências do público aflito, o Estado criou um decreto regulamentar estabelecendo que haveria um controle por funcionários do Estado dos barcos pesqueiros. Com a criação desta Legislação Simbólica o público se acalmou, o turismo e a economia restabeleceram, o Estado voltou a arrecadar, mas não houve ou quiçá planejou-se uma estrutura funcional, organizacional ou operacional para cuidar deste controle. A situação não sofreu qualquer modificação e o decreto permaneceu plenamente ineficaz, mas teve este papel de álibi tranquilizador para o público no sentido que o Estado estava preocupado e, estava atuando, sendo simplesmente um texto sem nenhum significado prático.

A Legislação Simbólica como fórmula de compromisso dilatório tem por função adiar a solução de conflitos sociais através de compromissos dilatórios. A aprovação do texto legal não se funda no conteúdo do diploma normativo, mas sim na transferência da solução do conflito para um futuro indeterminado. Exemplo citado refere-se às empregadas domésticas norueguesas. Havia uma proposta do partido socialista norueguês de integrar as empregadas domésticas nas legislações comuns dos demais trabalhadores, sendo que o partido liberal era contrário, estabelecendo um conflito sem soluções possíveis, pois os socialistas precisavam dar uma resposta para seu eleitorado e os liberais também. Assim chegou a um compromisso dilatório, aprovou a legislação em favor das empregadas domésticas e, ao mesmo tempo, se integrou a mesma lei uma cláusula sancionatória que tornava praticamente impossível a sanção dos empregadores. Este tipo de legislação apenas adia a solução de conflitos por meio de compromissos dilatórios, propondo soluções a serem implementadas em prazo 
indeterminado, ou seja, a lei foi aprovada com um texto que não teve nenhum significado prático na realidade jurídica e social.

Observa-se assim, uma função simbólica para servir ao sistema político latentemente, mas com um significado manifesto de norma jurídica inexistente.

Tais tipologias despertam para percepção que a problemática da Legislação Simbólica é extremamente complexa, não limitando à questão da irrelevância social da legislação ou da carência de eficácia normativa de certos textos legais, mas da própria ineficácia normativa, pois os efeitos seriam essencialmente políticos e não propriamente jurídicos.

\section{CONSTITUCIONALIZAÇÃO SIMBÓLICA DA AUTOPOIESE A ALOPOIESE DO DIREITO.}

Definida o que é legislação simbólica e apresentado à tipologia tricotômica, Marcelo Neves aprofunda a discussão analisando a questão da Constitucionalização Simbólica, apoiado no modelo sistêmico proposto por Niklas Luhmann que define a Constituição como acoplamento estrutural entre política e direito e como mecanismo que permite a autonomia operacional do direito na sociedade moderna:

Nessa perspectiva, a Constituição em sentido especificamente moderno, apresenta-se como uma via de "prestações" recíprocas e, sobretudo, como mecanismo de interpenetração (ou mesmo de interferência) entre dois sistemas sociais autônomos, a política e o direito, na medida em que ela "possibilita uma solução jurídica ao problema de auto-referência do sistema político e, ao mesmo tempo, uma solução política do problema de autoreferência do sistema jurídico" (NEVES, 2007, p. 65).

O modelo sistêmico proposto por Niklas Luhmann deriva da teoria biológica de Maturana e Varela (1980), que propunham a criação de um sistema a partir de outro sendo ambos distintos, mas com íntimos e numerosos pontos de contato, mas interdependentes, incorporando assim, às ciências sociais os conceitos de autopoiese.

Etimologicamente, o termo autopoiese deriva do grego autos (por si próprio) e poieses (criação) e, na teoria biológica, significa que um sistema é construído por seus próprios componentes. A produção, a transformação e a destruição de seus componentes realizam-se através de suas interações e transformações. Sistema e ambiente seriam independentes, daí falar-se que os sistemas são homeostáticos. 
Na teoria dos sistemas de Luhmann, diversamente da teoria biológica, a produção das relações entre sistema e ambiente é um elemento necessário para a reprodução: autopoiese, segundo o qual, um sistema é dito autopoiético quando este se reproduz primariamente com base nos seus próprios códigos e critérios, assimilando os fatores do seu meio-ambiente circundante (expectativas sociais), mas mantendo a sua autonomia e identidade perante os demais sistemas sociais.

Encarando-se o Direito enquanto sistema, Luhmann atesta que, sendo autopoiético, tem-se por premissa o código diferença lícito/ilícito como condição de sua auto-referência sistêmica, sendo que os valores e razões motivadores da norma, ainda que captados de diferentes fontes, devem buscar suas fontes nos próprios princípios norteadores para a criação, interpretação e aplicação jurídicas.

Neste sentido, um sistema mantém seu caráter autopoiético na medida em que se refere a si mesmo e ao seu ambiente. As mais diversas determinações do ambiente, no entanto, somente serão inseridas no sistema quando filtradas pelo código-diferença específico de cada uma das espécies dos subsistemas sociais.

Para Luhmann, um subsistema social tem como estrutura um código-diferença através do qual elemento externo (extrasistêmicos ou do ambiente) são inseridos que no direito é "lícito/ilícito".

$\mathrm{Na}$ teoria de Luhmann o direito é um sistema normativamente fechado, mas cognitivamente aberto, pois pode assimilar, de acordo com seu código-diferença, os fatores do ambiente (abertura cognitiva), não sendo diretamente influenciado por eles, porquanto a vigência jurídica de expectativas normativas depende de processos seletivos de filtragem no interior do sistema jurídico.

Nesse sentido, as diversas determinações do ambiente só são inseridas no sistema (abertura) quando este, de acordo com seus próprios critérios e código/diferença, atribui-lhes forma (fechamento). É a chamada autopoiese no direito.

Assim, todos os valores que circulam o discurso geral da sociedade são, após a diferenciação de um sistema jurídico, ou juridicamente irrelevante, ou valores próprios do direito. O fechamento operacional, o qual garante a autopoiese no direito, dá-se pelo 
código/diferença "lícito/ilícito": o responsável pela comutação dos fatos externos e a respectiva inserção no sistema.

Se, e somente se, um elemento "passar" por tal filtro, estar-se-á diante de um sistema jurídico autopoiético.

O poder econômico, político, religioso e outros para exercerem influência num direito organizado autopoieticamente, deve, sempre, passar por tais filtros, de modo que, se o direito não lhe autoriza a entrada, serão mero "ambiente".

A Constituição, enquanto mecanismo que permite a autonomia operacional do sistema jurídico, permite que o mesmo se desvencilhe de apoios externos, por isso ela aparece como condição da reprodução autopoiética do direito, pois possibilita seu fechamento normativo e operacional, bloqueando as expectativas conflitantes de comportamento que emanam do contexto hipercomplexo da sociedade.

Por outro lado, a "corrupção" do sistema significa exatamente o oposto disso: os elementos de outro sistema, sem passarem pelo filtro do código-diferença de um determinado subsistema, entram e permanecem neste.

Em outras palavras as fronteiras entre um subsistema e o ambiente diluem-se o que é definido como alopoiese, do grego alôs (um outro, diferente) e poieses (produção, criação), designando que o sistema se reproduz por critérios do ambiente:

O respectivo sistema é determinado, então, por injunções diretas do mundo exterior, perdendo em significado a própria diferença entre sistema e ambiente (NEVES, 2007, p. 65).

O direito alopoiético, nesse contexto, perde sua autonomia operacional e os agentes do sistema jurídico põem de lado o código-diferença lícito/ilícito e passam a conduzir-se com base em outros códigos como da economia (ter/não-ter), da política (poder/não-poder), dentre outros.

O comportamento deixa de orientar-se primariamente pela semântica jurídica dos modelos textuais da Constituição, para orientar-se primariamente por outros modelos sociais de conduta. 
O direito passa a ser instrumento da política que não raras vezes, atende o jogo de interesses de particulares contrários ao processo de concretização normativa, impondo-se à margem da Constituição, verificando-se uma tendência de privatização do Estado.

Desta feita, temos que a autopoiese é o contrário da alopoiese, de modo que a negação de um implica na presença do outro, sendo tais teorias de fundamental importância para dogmática jurídica brasileira, pois desvelaria o perigo das Legislações Simbólicas como obstáculos a concretização não apenas dos direitos fundamentais, mas da própria Constituição, pois a Constitucionalização Simbólica desempenha um ativo papel no sentido de encobrir problemas sociais, obstruindo a efetivação do Estado de Direito.

Nesse sentido, Marcelo Neves aponta que essa capacidade da Constitucionalização Simbólica encobrir problemas sociais pode ensejar dois efeitos: conduzir a um desgaste das Constituições Simbólicas cujo resultado seja a eclosão de movimentos sociais e políticos consistentes no sentido de transformações efetivas no sistema constitucional ou conduzir à apatia das massas e ao cinismo das elites, que lamentavelmente acreditamos ser o mais provável face a total descrença no Estado e ausência de lideranças.

Na perspectiva da alopoiese do direito, há na Constitucionalização Simbólica uma exploração do sistema jurídico pelo político e econômico, perdendo assim, as suas funções tanto regulação da conduta quanto a de asseguração de expectativas para atender primeiramente e efetivamente outros sistemas, problema apontado por Neves como específico dos países que compõem a modernidade periférica, nos quais seria recorrente o problema da auto-referência deficitária do sistema jurídico.

Parto da constatação de que o advento da sociedade moderna está intimamente vinculado a uma profunda desigualdade econômica no desenvolvimento inter-regional, trazendo consequências significativas na reprodução de todos os sistemas sociais, principalmente no político e no jurídico, estatalmente organizados (NEVES, 2007, p. 170).

A questão das grandes disparidades no interior de todos os sistemas sociais e também entre eles implica um enfraquecimento ou impossibilidade de seu funcionamento de maneira generalizadamente includente, fato destacado pelo autor:

A bifurcação no desenvolvimento da sociedade moderna (mundial) para os países periféricos em uma crescente e veloz complexificação social, sem que 
daí surgissem sistemas sociais capazes de estruturar ou determinar adequadamente a emergente complexidade (NEVES, 2007, p. 172).

Eclode assim, o problema da exclusão advinda da relação subintegração e sobreintegração que proporciona a expansão da esfera política, econômica em detrimento do desenvolvimento autônomo do direito pelo código diferença licito/ilícito.

Neste aspecto, o discurso legal passa a constituir-se como uma linguagem destinada a persuadir e a convencer, pois as fronteiras entre o direito e o ambiente não apenas se enfraquecem, mas desaparecem e o texto legal perde sua força de regulador de comportamento e de assegurador de expectativas e transforma-se num mecanismo de manipulação a serviço do político e econômico.

Como consequência, perde-se a crença no sistema jurídico e os destinatários do texto sentem-se enganados.

\section{CORRUPÇÃO SISTÊMICA}

Face a perda da operacionalidade do direito que deixa de responder adequadamente as exigências de seu meio ambiente social supercomplexo ou mesmo a deturpação do texto constitucional impedem seu processo concretizador e, inevitavelmente, mantem a CORRUPÇÃO SISTÊMICA.

E, não se trata de uma corrupção interna que pode ser imputada a alguém concretamente e o sistema consegue reagir, mas sim quando o próprio sistema não pode reagir, saindo do nível operativo, das operações, para o plano estrutural da estabilização das expectativas, ou seja, a segurança da impunidade se torne uma garantia, onde atuar na ilicitude é mais seguro do que seguir a legalidade, aquele que estivesse atuando conforme o modelo de ilicitude (dentro de um órgão estatal) teria mais segurança e mais tranquilidade na estabilização de suas expectativas.

Isso é a corrupção sistêmica estrutural porque implica em estabilização de expectativas normativas e vai bloqueando a reprodução consistente do direito e impede a constitucionalização e a legalidade.

Se a corrupção sistêmica se amplia, se generaliza, provoca no caso do sistema de direito, a incapacidade de concretização constitucional do Estado de Direito. 
O bloqueio reiterado do processo de concretização constitucional, decorrente da sobreposição destrutiva dos códigos binários de outros sistemas acarreta uma ampla relação de exclusão se considerarmos que a inclusão está relacionada ao acesso e dependência de pessoas ao sistema social, ou seja, dependo e tenho acesso, isso é inclusão, é a relação de dependência e acesso. Ao passo que exclusão não é o isolamento, mas a falta de um destes elementos: dependência e acesso.

Neste aspecto, Marcelo Neves bem destaca que há exclusão por cima (sobreincluídos) e a exclusão por baixo (subincluídos), diferenciando que são subincluídos os que têm os deveres, tem dependência, mas não têm os acessos e, sobreincluídos os que têm acessos aos benefícios, mas não sofrem as restrições desse sistema social.

A subinclusão significa dependência das exigências dos subsistemas da sociedade, mas não há acesso aos respectivos benefícios. No campo do direito, isso implica subordinação aos deveres impostos pela ordem jurídica, mas falta de acesso a direitos básicos. Já a sobreinclusão significa que certos setores privilegiados têm acesso aos benefícios dos sistemas sociais, mas não se subordinam às suas imposições restritivas, o que implica exercício dos direitos sem subordinação aos deveres.

Tais relações, no campo do direito, significam subcidadania e sobrecidadania e, esta situação bloqueia a partilha generalizada de direitos e deveres estatuídos no Estado de Direito demonstrando cada vez mais que os sobrecidadão nunca sofrem as consequências e sanções jurídicas.

O sobrecidadão se apresenta para o sistema como aqueles que têm direitos e prerrogativas, porém tem certa garantia perante os subcidadãos e perante a própria estrutura estatal que não está subordinado aos deveres e restrições estatais. Já os subcidadãos não tem acesso aos benefícios, mas o sistema funciona rigidamente contra ele.

Tais análises apenas ratificam que o problema estrutural é a falta de autonomia operacional dos sistemas, não apenas jurídico, mas também político que ficam bloqueados externamente por injunções diretas de critérios dos demais sistemas sociais, principalmente do econômico, vitro que são as injunções particularistas da dominação econômica que destroem a legalidade no plano jurídico e os procedimentos democráticos na esfera política. Já, internamente, por sua vez, não há um funcionamento satisfatório da Constituição como 
"acoplamento estrutural" entre direito e política, sendo necessária uma radical revolução nas relações de poder para a concretização normativa do texto constitucional, o que infelizmente nos parece utópico.

Apesar de utópico, é fato que a Constituição é o horizonte do agir e vivenciar jurídico e também político, por consequência seus atores deveriam se orientam pelos padrões constitucionais.

Contudo, os atores ao revés de deixarem-se guiar por este horizonte propõem sua reforma de forma tão insiste e corriqueira que passa a ser parte do próprio programa do governo, como claramente apontado por Neves:

A responsabilidade pelos graves problemas sociais e políticos é, então, atribuída à Constituição, como se eles pudessem ser solucionados mediante as respectivas emendas ou revisões constitucionais. Dessa maneira, não apenas se desconhece que as leis constitucionais não podem resolver imediatamente os problemas da sociedade, mas também se oculta o fato de que os problemas jurídicos e políticos que frequentemente se encontram na ordem do dia estão associados à deficiente concretização normativo-jurídico do texto constitucional existente, ou seja, residem antes na falta das condições sociais para a realização de uma Constituição inerente à democracia e ao Estado de direito do que nos próprios dispositivos constitucionais. No âmbito da retórica do reformismo constitucional, os programas de governo ficam reduzidos a programas de reforma da Constituição; estes são frequentemente executados (quer dizer, as emendas constitucionais são aprovadas e promulgadas), contudo as respectivas estruturas sociais e relações de poder permanecem intocáveis (NEVES, 2007, p. 187).

Isso oculta o fato de que os problemas jurídicos e políticos estão associados à deficiente concretização normativo-jurídica do texto constitucional existente.

Dentro desta retórica (reformismo constitucional) os programas de governo ficam reduzidos a programas de reforma da Constituição; as emendas constitucionais são aprovadas e promulgadas, contudo as respectivas estruturas sociais e relações de poder permanecem intocáveis.

Neste aspecto, Marcelo Neves aponta que quando se fala da reforma do Estado com a reforma da Constituição outro caminho não há que o engano, pois reforma do Estado é uma reforma de estrutura, implica uma reorientação dos agentes públicos e privados, uma reorientação das expectativas e, portanto, dos comportamentos o que não exige qualquer reforma da Constituição. 
Por outro lado, reforma Constitucional, em princípio, por si só, não implica reforma do Estado.

Reforma Constitucional é produção de texto constitucional, sendo que no Brasil toda vez que fala em reforma do Estado, se pensa em reforma ou emenda da Constituição e, assim, surgem modificações com caráter eminentemente simbólico, na qual o caráter latente, mostrar um Estado preocupado com esse problema, é muito mais relevante do que o caráter normativo.

Portanto, a reforma constitucional atua como álibi para fracassos, álibi da incapacidade de enfrentar problemas estruturais com competência, com capacidade governamental, deslocando toda esta incompetência para o próprio texto constitucional, invertendo-se o problema da Constitucionalização Simbólica e perdendo o horizonte constitucional.

Nesse caso há uma reconstitucionalização simbólica permanente que protela a questão fundamental que é a concretização constitucional.

Destarte, se fizéssemos o caminho reverso, ou seja, se tivéssemos uma ampla concretização normativa, teríamos não só a reforma, mas uma revolução, uma transformação profunda da realidade social e, por consequência autopoiese do direito.

\section{CONSIDERAÇÕES FINAIS:}

Apesar das implicações apontadas no trabalho e da tardia inserção do tema abordado por Marcelo Neves no Brasil, ainda assim, temos ser de suma importância o aprofundamento nos estudos da Legislação Simbólica, principalmente acerca da Constitucionalização, pois serve de norte para buscar a efetiva concretização dos preceitos constitucionais, o que, de certa forma, já vem sendo adotado pelo Judiciário através do chamado ativismo judicial, por meio do qual o judiciário tem buscado a efetiva implementação das normas constitucionais superando seu caráter meramente retórico e simbólico de seus preceitos.

Contudo, esta não é a solução. A premissa básica e essencial de um Estado de Direito é que seja autopoiético, que mantenha sua auto-referência sistêmica, sendo que os valores e 
razões motivadores da norma, ainda que captados de diferentes fontes, busque suas fontes nos próprios princípios norteadores, principalmente a Constituição, para a criação, interpretação e aplicação jurídica, o que implicará em legalidade, fator fundamental ausente na alopoiese.

O debate central não poder ser o reformismo constitucional, que é mero álibi do Estado, mas deve focar em devolver ao sistema jurídico sua legalidade através da autopoiese que consequentemente evitará tantas Legislações Simbólicas que atendem interesse do sistema político e econômico com grandes vantagens para os sobrecidadão e graves prejuízos para os sobrecidadão.

Por fim, importante destacar não só a erudição do autor Marcelo Neves, mas a grandiosidade de suas teorias inovadoras indispensáveis ao debate jurídico-científico, que pensadas e escritas em 1992 mostram-se reveladoras do atual contexto político vivenciado pelo Brasil.

\section{BIBLIOGRÁFICAS CONSULTADAS:}

ARNAUD, Andre-Jean; Lopes Jr., Dalmir. Niklas Luhmann: Do sistema social à sociologia jurídica. Rio de Janeiro: Lumen Juris, 2003.

BRASIL. Constituição da República Federativa do Brasil de 1988. Disponível em: http:www.planalto.gov.br.

ECO, Umberto. Semiótica e Filosofia da Linguagem. Trad. Milton Mariarosaria Fabris e José Luis Fiorin. São Paulo: Ática, 1991.

KELSEN, Hans. Teoria Pura do Direito. Traduzido por João Baptista Machado. São Paulo: Martins Fontes, 1998.

NEVES, Marcelo. A constitucionalização simbólica. São Paulo: WMF Martins Fontes, 2007.

TRINDADE, André Fernando dos Reis. Para entender Luhmann e o direito como sistema autopoiético. Porto Alegre: Livraria do Advogado Editora, 2008. 